\title{
David Moriente
}

\section{PAISAJES URBANOS DE LA CIENCIA FICCIÓN ${ }^{*}$}

Una ciudad del futuro como nunca llegaron a ser las ciudades del futuro y cómo se las imaginaba en tiempos en los que 1986 era algo que quedaba tan lejos como otro planeta. Detalles de edificios altos y con formas de esferas y un cohete al que ascendían personas listas para emprender el viaje y, en primer plano, sobre una especie de mirador curvo, un hombre y una mujer enfundados en trajes espaciales, sosteniendo sus cascos con sus manos, miraban a lo alto, contemplando el paso del cometa.

-Rodrigo Fresán ${ }^{1}$

\section{Exordio}

Nunca es fácil seguir los pasos de tu maestro, sobre todo cuando las cotas a las que llegó Juan Antonio Ramírez son tan altas que la posibilidad de aproximación se

\footnotetext{
"Este texto apareció originalmente en Julián Díaz y Carlos Reyero (eds.), La historia el arte y sus enemigos. Estudios sobre Juan Antonio Ramírez, Ediciones de la Universidad de Castilla-La Mancha, Ciudad Real y Ediciones de la Universidad Autónoma de Madrid, Madrid, 2010, pp. 107-127 y se reproduce aquí con permiso del autor.

Nota del autor: Solamente una nota preliminar en relación con el contenido de algunas aseveraciones e interpretaciones ubicadas en el presente trabajo. Cuando Anna María Guasch me propuso la posibilidad de reeditar el homenaje a nuestro querido maestro, el desaparecido Juan Antonio Ramírez, estuve tentado a revisar algunos aspectos que mi "yo del pasado" escribió y con los que en la actualidad me encuentro disconforme-los eventos de la historia reciente han influido enormemente, sin duda -, pero tal acto hubiera sido traicionar el espíritu original que concibió y animó este texto. Por este motivo, obro en consecuencia y "Paisajes urbanos de la ciencia ficción" aparece tal cual se escribió hace tres años.

${ }^{1}$ El fondo del cielo, Mondadori, Barcelona 2009.
} 
torna poco menos que misión imposible. Investigador perseverante como pocos, ningún asunto le parecía despreciable o carente de importancia, al contrario, siempre era capaz de exprimir a conciencia cualquier destello de información y organizar los datos para ofrecer una interpretación sorprendente y original. Una de las razones por las que me sentí atraído hacia su órbita-igual que muchos de mis colegas-cuando yo no era más que un estudiante de bachillerato fue, no sólo su excelente modo de escribir, sino el hecho de que se ocupara de cosas raras que, generalmente, no aparecían en los libros académicos, como era el caso del cómic o el cine fantástico, y que me interesaban sobremanera. En este sentido, he querido ofrecer una visión-no lo oculto-absolutamente mediatizada por sus enseñanzas y he intentado enseñar lo que he encontrado en aquellos parajes ficticios. "Traed algo de vuelta de la exploración”, habría dicho él con su habitual sentido del humor.

Juan Antonio Ramírez siempre mantuvo un estrecho diálogo con el pasado y el futuro o, en otros términos, con el vínculo existente entre la memoria y la imaginación, siendo los elementos representativos necesarios para cualquier construcción simbólica. Una de sus últimas argumentaciones más atractivas se dirigía hacia la noción de lo futurible. Si éste es, según el Diccionario de la $R A E$, "lo que no será con seguridad, sino que sería si se diese una condición determinada”, en lo concerniente a nuestra disciplina equivaldría a afirmar que dadas ciertas manifestaciones se pueden predecir y esclarecer efectos bien determinados. Enigmas y problemas artísticos del pasado se pueden explicar a la luz del presente y viceversa, con respecto a los comportamientos contemporáneos. Lo que en un período puede ser malinterpretado (literalmente) en tanto que aberración, anomalía o extravagancia, en otro se puede leer de una manera más coherente aunque no definitiva. Un ejemplo paradigmático sería la exégesis de determinados elementos figurativos de la pintura de El Bosco con las lentes surrealistas. ${ }^{2}$ Resulta llamativo que el surrealismo sea, precisamente, un género fundado en lo fantástico y dado a ambientar todo aquello que se encuentra fuera de los límites de lo cotidiano; de ahí no es de extrañar, pues, que, por ejemplo,

\footnotetext{
${ }^{2}$ Ramírez, Juan Antonio (2005). “El Bosco: futurible divino y paraíso invertido” (introducción), en el libro de Franca Varallo, Bosco. Los grandes genios del arte, Madrid: Biblioteca El Mundo, 723.
} 
Hitchcock escogiera los escenarios de Dalí para ambientar la sordidez de los recovecos de la memoria en Spellbound (Recuerda, 1945).

Uno de nuestros puntos de encuentro se hallaron, sin duda, en esa simpatía hacia lo ilusorio. Si bien yo siempre me sentí más atraído por lo tecnocientífico antes que por lo onírico; no obstante, incluso a ese mismo asunto se dedicó Juan Antonio Ramírez. Es precisamente en este punto en el cual deseaba tomar como referencia algunas líneas de salida del capítulo que cerraba el genial libro Construcciones ilusorias. Arquitecturas descritas, arquitecturas pintadas, dedicado a la prospectiva y la ciencia ficción en el campo de la arquitectura. ${ }^{3}$ Con todas estas nociones en mente he revisado algunas delimitaciones de ese punto ciego que produce más interés en tanto que fenómeno cultural, tal es el caso de los análisis de Fredric Jameson, ${ }^{4}$ que como materia prima para la historiografía artística. Lo tecnofantástico no se reduce únicamente a un género convencionalizado sino que también configura un espacio que está repleto de tiempos lentos y largos, de sueños y pesadillas (arquitectónicas, claro) y, por supuesto, de realidades alternativas y utopías a las que era tan proclive a estudiar Ramírez.

Hasta hace relativamente poco, la ciencia ficción había corrido la misma suerte que todos los mestizos habidos de uniones poco canónicas, que sufrían el desprecio y la marginación de sus progenitores. Las disciplinas atacaron a su heredero bastardo: la ciencia consideró a la ciencia ficción como un alarde de fantasía sin límites al tiempo que la literatura la rechazó considerándola un género de segunda categoría. Pero, aquellas "narraciones extraordinarias" favorecieron la obra de Ray Bradbury o Philip K. Dick, incluidos en la alta cultura en el mismo escalafón que Shakespeare o Cervantes recientemente, pues como argumentaba en 1971 Thomas D. Clareson "en la última década [de los sesenta] la ciencia

\footnotetext{
${ }^{3}$ Ramírez, Juan Antonio (1983). "Prospectiva y ciencia-ficción (ciudades y edificios del futuro)”, en Construcciones ilusorias. Arquitecturas descritas, arquitecturas pintadas, Madrid: Alianza, 217-247.

${ }^{4}$ Jameson, Fredric (2005). Archaeologies of the Future: The Desire Called Utopia and Other Science Fictions, Londres: Verso. Existe traducción al castellano: (2009). Arqueologías del futuro. El deseo llamado utopía y otras aproximaciones de ciencia ficción, Akal, Madrid.
} 
ficción ha conseguido respetabilidad académica y por parte de la crítica motivada por su interés hacia los temas utópicos y distópicos". 5

Lo fantástico ha acogido en su seno laboratorios donde madurar nuevas ideas, que aspiraban a desarrollar estados y ciudades utópicas; en este sentido, se podrían citar infinidad de ejemplos acoplados a la misma matriz que irían de la República de Platón a la Ciudad del Sol de Campanella. A pesar de todo ello, es desde el último tercio del siglo XIX en adelante donde se sitúa el punto de inflexión, dado que comienza a revelarse el progreso tecnológico como factor relevante de la narración cuyas muestras más visibles son las de Jules Verne y Herbert G. Wells. Con posterioridad habrá una intensa corriente de literatura popular-además profusamente ilustrada-que influirá decisivamente en el imaginario fantástico aplicado a la arquitectura y urbanismo ulteriores, manifestada en las revistas baratas de los años veinte. En 1926, solamente había una dedicada a la ciencia ficción, Amazing Stories, editada por Hugo Gernsback, pero a finales de la década salieron al mercado publicaciones como Astounding o Wonder Stories y en los años treinta ya había más de una docena de ellas. ${ }^{6}$ Uno de los aciertos del hábil Gernsback-quien, por cierto, tuvo el olfato de reconocer el gancho comercial del joven Isaac Asimov en los años cuarenta-fueron las portadas ilustradas por la desbordante imaginación de Frank R. Paul que atrajeron a una ingente cantidad de seguidores.?

Las construcciones canónicas o, dicho de otro modo, los "hechos arquitectónicos", estarían inscritos en la esfera de una noción que, aunque diseñada por Nöel Burch para el cine, ${ }^{8}$ hemos tomado prestada por su

\footnotetext{
${ }^{5}$ Clareson, Thomas D. (ed.) (1971). "Introduction: The Critical Reception of Science Fiction", en SF: The Other Side of Realism, Bowling Green, Ohio: Bowling Green University Popular Press, ix. Por otra parte, merece la pena detenerse en el comentario realizado por el catedrático de física del City College of New York Michio Kaku hacia las convenciones de la ciencia ficción desde la perspectiva del conocimiento científico en (2009). Física de lo imposible: ¿podremos ser invisibles, viajar en el tiempo, teletransportarnos?, Barcelona: Debate.

${ }^{6}$ Robinson, Frank M. (1999). Science Fiction in the $20^{\text {th }}$ Century. An Illustrated Story, Portland, Oregon: Collectors Press, 60.

${ }^{7}$ Rarmírez, "Prospectiva y ciencia-ficción (ciudades y edificios del futuro)", 220 y 238.

8 "Por otra parte, si hay una justificación de mi empresa en los planos ético y social, es a partir de esta constatación: millones de hombres y de mujeres a quienes se les enseña a leer y a escribir 'sus cartas', no aprenderán más que a leer las imágenes y los sonidos, y por tanto sólo podrán recibir su
} 
pertinencia. Hablamos del modo de representación institucional para expresar que la arquitectura es un lenguaje diseñado con una gramática específica que pocos pueden hablar y entender, mientras que una inmensa mayoría solamente puede acatar su fundamento, sin capacidad para reproducirlo; su representación ("hacer presente") está determinada por el establecimiento de la práctica constructiva. Por contra, las no-edificaciones y otros proyectos de raigambre más o menos fantástica, las "ficciones arquitectónicas", se pueden entender en tanto que modelos alternativos a ese lenguaje y, también, como gran parte de la definición de utopía.

Las raíces de ambos, hecho y ficción, se hunden en la propia génesis de la arquitectura. El ser humano no es el único animal que construye, ni mucho menos: los estudios que versan sobre la denominada "arquitectura animal" han revelado la emergencia del impulso constructivo de muchas especies, sobre todo en los períodos estacionales de cría; ${ }^{9}$ sin embargo, el ser humano, al carecer de dichos períodos y, por tanto, poseer una reproducción continua, motivaría un comportamiento edificatorio que traería consigo más una ruptura que una continuidad respecto del proceder zoológico. Resulta curioso observar que los primates, a diferencia de otros animales constructores, no parecían estar especialmente dotados para la arquitectura. En efecto, como afirma Juhani Pallasmaa, "no deja de sorprender y de ser motivo de especulación el hecho de que las construcciones de los animales de especies superiores se encuentran entre las menos ingeniosas de todo el reino animal" ${ }^{10}$

A pesar de ello, la cultura humana ha desarrollado un obstinado proceso de sometimiento del espacio natural a través de la urbanización. El rumbo que han seguido los asentamientos humanos, desde la aldea neolítica a las megalópolis del siglo XXI, no se puede considerar en modo alguno un fenómeno lineal. Contrariamente, forma un cúmulo de avances, retrocesos y pérdidas que

discurso como 'natural'. Burch, Nöel (1987). El tragaluz del infinito (Contribución a la genealogía del lenguaje cinematográfico), Madrid: Cátedra, 17.

9 Pallasmaa, Juhani (2001). Animales arquitectos: el funcionamiento ecológico de las construcciones animales, Lanzarote: Fundación César Manrique.

10 "Las construcciones de los simios, por ejemplo son cobijos hechos de cualquier modo, justo para pasar la noche, comparadas con las metrópolis de las termitas, que tienen millones de habitantes y que, según ha sido observado, son utilizadas durante siglos”. Ibíd., 12. 
dificultan su estudio. La ciudad no constituye un hecho neutral, pero lo que parece invariable en el progreso urbano son dos aspectos: de una parte, la ejecución del recinto que sirve para instalar a todos los que son relativamente afines. Así, con distintos nombres y finalidades, todos albergan personas, la industrial Manchester, la seudoutópica muestra del New Urbanism en Seaside o el matadero fordista de Auschwitz. Por otra parte, el factor socioeconómico, por el que se distinguen la mayor o menor riqueza del lugar, las potenciales relaciones comerciales entre territorios y las redes ideológicas que se pueden asentar en la comunidad, lo que invariable y cíclicamente conduce a la civilización. ${ }^{11} \mathrm{La}$ arquitectura con sus construcciones-públicas, privadas, monumentales-y sus ciudades se constituye como la carta de identidad, el indicio, el trayecto y el vestigio de que lo humano ha franqueado los límites naturales. A pesar de la existencia a lo largo de la historia de edificaciones de considerable altura podemos interpretar la llegada del Movimiento Moderno como el contagio de una suerte de síndrome de la torre de Babel, un deseo continuamente insatisfecho de conquistar los cielos.

\section{Consumo, represión, exclusión y clonación}

Resulta obvio que la faz del mundo ha cambiado radicalmente en los últimos cuarenta años. La barrera de los 2000 todavía constituía un horizonte de sucesos en el cual todavía era posible la transformación positiva, el apogeo de los ideales de la modernidad, en suma, la realización de la utopía; pero el deterioro se conformó en el "hundimiento moral" de 1968 y el "económico" de $1974 .{ }^{12}$ En efecto, a finales de la década de los sesenta, con el fracaso revolucionario del Mayo del 68, se aprecia con nitidez el cambio drástico en aquella esperanza, el punto de inflexión donde se percibe la imposibilidad; desgraciadamente, son correctos los análisis de Marcuse, pues los proyectos de cambio social se tornan en algo ilusorio. ${ }^{13}$ La utopía es, sencillamente, antagónica con la realidad cotidiana: el desacuerdo entre el concepto y su marco histórico es tal que se ha producido su

\footnotetext{
${ }^{11}$ Kotkin, Joel (2006). La ciudad. Una historia global, Barcelona: Debate.

${ }^{12}$ Esparza, José Javier (1994). "Vindicación de la posmodernidad", en Ejercicios de vértigo.

Ensayos sobre la posmodernidad y el fin del milenio, Madrid: Barbarroja, 76.

${ }^{13}$ Marcuse, Herbert (1986). El final de la utopía, Barcelona: Ariel.
} 
disolución irreversible. El escenario de este período entre siglos ha intensificado aspectos en la arquitectura y la ciudad que chocan frontalmente con su noción.

Como instrumento de propaganda, la arquitectura ha desempeñado un papel idóneo a lo largo de su dilatada tradición: las edificaciones soberanas, ya fueran efímeras o definitivas, demostraban a los estamentos inferiores quiénes ostentaban el poder (que en muchos casos también detentaban) y quiénes establecían las reglas de dominio en un determinado período. Las nuevas arquitecturas áulicas son al plano constructivo lo que el poder al plano político e ideológico: cambian los elementos representativos-las formas políticas y arquitectónicas-pero siguen existiendo relaciones de autoridad con respecto a los ciudadanos. Así el nexo amo-siervo en cualquiera de sus variantes ha evolucionado en una relación de compañía-cliente mediante un ajuste en favor del consumo como un dispositivo de férreo control.

Una de las formas de ejecutar ese control por parte de la arquitectura, es mediante el sutil ejercicio del mecanismo represor: la relación de vasallaje se ha sustituido por otra más duradera de producción y consumo. A través de las hipotecas, por ejemplo (en inglés, con el tenebroso nombre de mortgage), se consigue un enlace casi vitalicio con la entidad bancaria que retarda la manumisión personal. Habría que hacer rendir cuentas al universo mercantil en su conjunto puesto que la arquitectura se encuentra implicada en escándalos financieros, "burbujas inmobiliarias” y “tramas urbanísticas”. Pero también a través de la presión física al individuo: podemos establecer el símil el jardinero japonés que poda constante y pacientemente las ramas de un árbol para evitar que crezca y así transformarlo en un bonsái; la construcción de viviendas al límite de la superficie habitable está presionando, al ciudadano. ${ }^{14}$ Así, a través de esta represión (también en el sentido de "volver a presionar") se obtienen sujetos cuya expresión del raquitismo mental y político es manifiesta.

\footnotetext{
${ }^{14}$ En el ámbito de la Comunidad de Madrid, por ejemplo, Infraviviendas serían aquellas cuya superficie habitable está por debajo de los veinticinco metros cuadrados, véase el Plan General de Ordenación Urbana (PGOU), Boletín Oficial de la Comunidad de Madrid, Madrid 1997, s.p. Léase la noticia del diario El Mundo, "Alquilo 'casa' de $9 \mathrm{~m}^{2}$ en el centro de Madrid por 600 euros mensuales”, viernes, 27 de febrero de 2004.
} 
La creciente deshumanización de los asentamientos periféricos de las ciudades se basa en la apariencia racional de la nueva planta, que les confiere un engañoso aire de comodidad y cierto aspecto inquietante. Hay una impresión de vacío emocional con respecto al entorno urbano: barriadas de aire moderno, pero inhóspitas al fin y al cabo. Éstas se hallan emparentadas con las llamadas "ciudades-dormitorio" tan extendidas en los años sesenta y setenta del siglo

pasado. No obstante, la proliferación de asentamientos replicados entre sí se puede dividir en dos tipos completamente contradictorios: de una parte, lo que en el ámbito anglosajón se ha dado a llamar la gated city con una población de clase media acomodada o incluso media-alta, que forma una barrera de exclusión socioeconómica con respecto de los otros, fuera de su blindaje protector; ${ }^{15} \mathrm{de}$ otra, los subestratos marginales se organizan en laberínticas barriadas sin acceso al mínimo de bienestar social. Las periferias de las ciudades, pues, se autorreplican como virus descontrolados y contienen tanto suburbs, suburbia, zonas residenciales como chabolas, shantytowns, favelas, bidonvilles; centros comerciales, malls, megastores. Todos ellos como productos estandarizados sin señas de identidad; se combinan arbitrariamente las edificaciones con otros componentes urbanos-como si fueran accesorios-fuentes, rotondas, plazas, parques; servida la homologación espacial es difícil que no entre en escena una mediocridad anodina en los habitantes con una endogamia cultural cada vez más evidente.

La ciudad como medida humana sufre de una patología que podríamos denominar teratourbanismo acelerado. El equilibrio que debía existir como principio organizador del espacio urbano ha cedido el paso ante la presión monstruosa del caos generado por la voracidad de las factorías inmobiliarias. La culpabilidad recae en el sistema capitalista que cuida de que el conjunto funcione de un modo óptimo para producir más consumidores que produzcan y consuman más, en un encadenamiento infinito. Los residuos de esa acción cristalizan en el junkspace, el espacio-basura que es, en palabras de Koolhaas, "lo que queda

\footnotetext{
${ }^{15}$ Amendola, Giandomenico (2000). "Los excluidos del sueño y la ciudad blindada", en La ciudad postmoderna. Magia y miedo de la metrópolis contemporánea, Madrid: Celeste.
} 
después de que la modernización haya seguido su curso o, más concretamente lo que se coagula mientras la modernización está ocurriendo su secuela”. ${ }^{16}$

\section{Dialéctica de fantasías y realidades: notas para una historia de la arquitectura-ficción}

En el año 1889, el escritor y grabador John A. Mitchell publicó el breve libro The Last American donde el almirante Khan-Li (ide la marina persa!) exploraba los vestigios de la desaparecida cultura estadounidense en el remoto año 2951, llegando incluso a navegar el río Hudson bajo las amenazantes ruinas del Puente de Brooklyn. ${ }^{17}$ Es sumamente atractivo observar la traslación de agentes y objetos desde nuestros patrones actuales: los persas (los malvados iraníes atómicos) finalmente han conseguido hollar el territorio norteamericano en una expedición cautivada por las maravillas del pasado perdido de Mehrikha. Proyección, construcción y destrucción forman parte de un ciclo ininterrumpido que permite observar la evolución de las formas arquitectónicas y sus ramificaciones o alineaciones no siempre predecibles.

Este ejemplo sirve de excusa para tomar contacto con la irrealidad de la práctica constructiva o, dicho de otro modo, con la expresión de las "ficciones arquitectónicas" que se encuentra opuesta (pero íntimamente relacionada) a los "hechos arquitectónicos" reales y fehacientes. Sin embargo, a principios del siglo pasado, se entremezclaban y contaminaban mutuamente ambas visiones, sin llegar a detectar discontinuidades en ellas, en un todo armónico. Uno de los ejemplos sería el pronóstico de las ciudades encapsuladas que, como veremos, será retomada periódicamente en tanto que pretexto para desarrollar argumentos más o menos utópicos. Así, la marca alemana de cacao Hildebrand en 1900 ofrecía al público infantil a través de cromos las exóticas predicciones, pero acertadas, tales que Überdachte Stadt im Jahre 2000 (Ciudad cubierta en el año 2000); multiestratos

\footnotetext{
${ }^{16}$ Koolhaas, Rem (2000). “El espacio basura. De la modernización y sus secuelas”, en Arquitectura Viva, 74, septiembre-octubre, 23-31.

${ }^{17}$ Mitchell, John A. (1889). The Last American. A Fragment from the Journal of Khan-Li, Prince of Dinph-Yoo-Chur and Admiral in the Persian Navy, Nueva York: Frederik A. Stokes \& Brother.
} 
urbanos que volverán a aparecer en los años sesenta de la mano de nombres tan dispares como Yona Friedman, y su proyecto para París Ville Spatiale (19581959), o la New Babylon del situacionista Constant (Constant Nieuwenhuys).

Antes de que el significado del adjetivo futurista quedara anclado para siempre con las vanguardias, la noción del progreso tecnológico indefinido, optimista y positivista ayudó a sentar los pilares del avance arquitectónico. Los alardes constructivos sembraban las imágenes de ciudades absolutamente modernas con el suplemento de elementos ya existentes aunque en posiciones algo distintas de las habituales. Así, ferrocarriles elevados, dirigibles atracados en las azoteas de los edificios o sobrevolando las avenidas y pasadizos y transportes subterráneos, contextualizados comercialmente, eran carta de presentación de grabados que poblaban los suplementos dominicales de los diarios de mayor tirada. ${ }^{18}$ ¿Cuántos de estos componentes se trasladaron a la esfera de lo real? No hay más que darse un paseo por la ciudad de Nueva York para percibir las resonancias de las bases arqueológicas del futuro: la calzada en un nivel superior alrededor de la Grand Central Station, el tren elevado en Bronx, Queens o Harlem, el remate del Empire State Building que serviría de repostaje de aeronaves o cualquiera de los actuales centros comerciales con galerías en los niveles del subsuelo. El ambiente de "promodernización" de la primera década del siglo XX caldea las mentes tanto de los ilustradores como las de los urbanistas. Si no, no se pueden entender los audaces motivos absolutamente visionarios de San't Elia en Cittá nova (19131914) ni los proyectos de renovación, en los siguientes años, de Le Corbusier para París en el Plan Voisin (1920). ${ }^{19}$

Otro tanto se puede afirmar de la influencia, más que probable, de los architekton de Kassemir Malevitch en la liberación del espacio urbano de las ataduras de la arquitectura tradicional. Si a la combinatoria de los elementos formalesparalelepípedos-se le asocia la idea de escala constructiva, entonces éstos se

\footnotetext{
${ }^{18}$ La Biblioteca del Congreso de los Estados Unidos, en su departamento de Grabados y Fotografías, posee una colección considerable de imágenes provenientes de orígenes tan dispares como la ilustración periodística o la tarjeta postal. Algunas de sus imágenes coinciden en aspecto con las ilustraciones de libros tales como Webb, Aston (1921). London of the Future, Nueva York: E. P. Dutton \& Co.

${ }^{19}$ Jeanneret-Gris, Charles-Édouard (Le Corbuiser) (1978). Hacia una arquitectura (1920-21), Barcelona: Poseidón.
} 
pueden comprender en tanto que edificios. En efecto, la concepción híbrida de las formas de Malevitch, entendidas a medio camino entre lo escultórico y lo arquitectónico, abre nuevos modos de plantear el edificio: los volúmenes adosados que surgen desde la base del núcleo central prismático ascienden, de modo asimétrico, hasta distintas alturas para articular de manera inédita y espectacular el ente construido. Los rascacielos escalonados y con ritmos modulares se hacen frecuentes en el imaginario popular urbano como lo demuestran las ilustraciones del arquitecto Hugh Ferris, The Metropolis of Tomorrow (1929).$^{20}$ (Hemos de recordar, que hasta el año 1931 no se terminó de construir el Empire State Building, con una delineación análoga a los citados architekton).

La amalgama de factores reales y ficticios eclosiona en la generación de uno de los más importantes e influyentes constructos para la cultura visual: Metropolis (Fritz Lang, 1927). Con respecto a nuestro tema, nos interesan más las consecuencias que se derivan de su puesta en escena que su importancia en tanto que film: la dirección artística corrió a cargo de Otto Hunte, Erich Kettelhaut y Karl Vollbrecht, así como los diseños de carteles de Boris Bilinski; todos ellos bajo las órdenes de Lang quien, muy probablemente, fascinado por la magnitud de Nueva York en su primer viaje, ejercería presión sobre ellos para desarrollar una imagen fantástica de la ciudad del futuro. ${ }^{21}$ Ésta sería muy distinta, un apretado conjunto de edificios a distintos niveles, con pasarelas y trenes elevados, que en su visión descoyuntada, huye de las amplias avenidas futuristas. Además la metrópolis de Lang estaba acompañada de dos inventos esencialmente necesarios para comprender la tecnología del siglo XX: la luz eléctrica, en concreto los rótulos de neón y los aeroplanos, cuya efectividad fue bien comprobada en la reciente Gran Guerra.

Además del aspecto estilizado y de su inequívoco eclecticismo, uno de los aciertos de la imagen de Metrópolis fue la introducción de la gigantesca magnitud de la

\footnotetext{
${ }^{20}$ Véanse Ferriss, Hugh (2005). The Metropolis of Tomorrow, Nueva York: Dover Books, y Gatland, Kenneth (1981). Ciudades futuras. La vida cotidiana en el siglo XXI, Madrid: Plesa. ${ }^{21}$ Fritz Lang admitió su inclinación hacia los contenidos más visuales del filme y afirmó que la primera idea le asaltó durante un viaje a Nueva York para promocional El anillo de los Nibelungos (1924). Véase Neumann, Dietrich (1996). Film Architecture: Set Designs from Metropolis to Blade Runner, Múnich: Prestel.
} 
ciudad en su conjunto. Las urbes futuras no solamente debían ser moderna y eléctricas, sino también enormes, las megalópolis. Es bien sabido el magnetismo que ejerció esta película sobre Adolf Hitler, quien veía en las imágenes de Lang la noción falseada del Übermench nietzscheano, y derivado de él, que atrajera muy probablemente también, a su protegido y, asimismo, futuro constructor de la retórica arquitectónica nacionalsocialista del Tercer Reich, el joven arquitecto Albert Speer. Que los regímenes totalitarios adoran lo ciclópeo es una de las características que comparten. Sin embargo, no deja de ser impresionante las concomitancias que unen, visualmente, al realismo socialista y al heroísmo nazi durante la década de los años treinta. Las perspectivas de Boris Iofan en los proyectos de ampliación para Moscú se podrían situar sin que supusieran discontinuidad alguna, con las maquetas del “Gran Berlín”. Este punto de convergencia se pudo comprobar, sin duda alguna, en la expresión de los pabellones de la Unión Soviética (Iofan) y Alemania (Speer) para la Exposición Universal de París del año 1937: puestos uno frente a otro y sin sus insignias, hubiera costado decidir a quién pertenecía uno y otro.

Al acabar la Segunda Guerra Mundial se puede observar una tendencia que permea el resto del imaginario fantástico: proveniente del estado de bienestar norteamericano, las construcciones tecnológicas guardan un asombroso parecido con la vida cotidiana y se estilizan y colorean profusamente. Bien es cierto que el fantástico europeo no parece seguir las directrices generales de ese movimiento colonizador y, por qué no, marshalliano, pero se están sentando de manera indudable las bases del pop. Las ciudades fantásticas de Alex Raymond son estilizaciones in extremis del art decó aerodinámico tan de moda por aquellos años en el cine; ${ }^{22}$ y de este medio toma también la configuración de los héroes, heroínas y villanos.

Pero el aire optimista pronto quedará ensombrecido por la carrera armamentística que alimentaba la Guerra Fría y el enfrentamiento dialéctico entre las dos potencias rivales. El peligro atómico no lo será tanto por la capacidad masiva de destrucción sino también por su propagación lenta, a través de la radiactividad. Parece imposible no preguntarse por qué comienzan a proliferar de

${ }^{22}$ Ramírez, Juan Antonio (1993). La arquitectura en el cine. Hollywood, la Edad de Oro, Madrid: Alianza. 
nuevo-ya no para guarecerse de las inclemencias "normales" del tiempo sino de los rigores del invierno nuclear-ciudades cubiertas bajo cúpulas geodésicas. Una idea que no era nueva dentro de la corriente utópico-constructiva, pues el escritor y sociólogo británico John Ruskin ya en 1854 se imaginó la ciudad de Middlesex cubierta por una "piel de cristal". ${ }^{23}$ Así pues, la imaginación de los ilustradores concebía domos transparentes, cristalinos, de una pieza, como si de una quesera colosal se tratara; los arquitectos e ingenieros, a su vez, ideaban soluciones factibles como la cubierta geodésica construida con módulos hexagonales del Climatron de Richard Buckminster Fuller (1963), o los neumocósmicos proyectos de Haus-Rucker-Co de mediados de los años sesenta, espacios alternativos en el interior de utópicas burbujas flotantes. Un ejemplo de la aplicación práctica de todos esos elementos lo constituye el Eden Project de Nicholas Grimshaw que, inaugurado en Cornualles en 2001, participa de toda una corriente discursiva que se situaría a medio camino entre la sostenibilidad, la necesidad de protección del medio ambiente y la armonía cósmica de la New Age.

El ejemplo del Climatron de Fuller ha generado una interesante fuente iconográfica. Formando parte del cuerpo principal del Jardín Botánico de Missouri, su inconfundible cúpula geodésica ha sido imitada tanto dentro como fuera de la arquitectura real. En 1972, Douglas Trumbull rodó el filme de bajo presupuesto Silent Running, una historia con ciertos tintes ecológicos ambientada en el espacio. Las astronaves Berkshire y Valley Forge, básicamente unas reservas de biodiversidad vegetal en órbita, fueron diseñadas a partir de varias citas visuales de proyectos de Fuller. Otra referencia explícita se manifiesta en el diseño de producción-labor de Dale Hennesy, quien no había trabajado antes en producciones de calado fantástico y, por cierto, se nota-de la película Logan's Run (La fuga de Logan, William F. Nolan, 1976) ambientada en la ciudad de Las Cúpulas, todas ellas muy similares a las formas geodésicas del arquitecto. Lo más interesante, sin duda, es la pirueta ejecutada por el artista finlandés Olafur Eliasson, quien en 2003 desarrolló la instalación Silent Running en tanto que un conjunto de elementos que homenajeaban tanto la vertiente ficticia de la construcción en el film, como la factible de realizaciones

\footnotetext{
${ }^{23}$ Cfr. Cohen, Jean-Louis (1996). "Utopia and Metropolitan Challenge, 1870-1935), en Uzawa, Takashi (ed.), Archaeology of the future city, Tokyo: The Tokyo Shinbun, 187.
} 
arquitectónicas, todo ello inscrito en el marco del Palacio de Cristal del Parque del Retiro de Madrid, herencia de la arquitectura en hierro de Joseph Paxton. ${ }^{24}$

La transacción entre los componentes reales y los imaginarios de la expresión arquitectónica establece un proceso de movimiento continuo. El escritor de ciencia ficción Robert Silverberg escribió en 1971 The World Inside (El mundo interior), un conjunto de retratos-casi sin trama-que abarcaban distintos aspectos de la hipotética vida cotidiana del siglo XXIV, dentro de unos colosales rascacielos, verdaderas ciudades verticales (las denominadas en el libro mónadas urbanas, "monurbs"); edificaciones que, con una ejecución bien definida y estandarizada, medían unos tres kilómetros de altura y podían llegar a cobijar alrededor de un millón de personas. La percepción de esos individuos se limita a un espacio interior edificado como metáfora del mundo real y un mundo exterior inhóspito y fantástico. De ello se infiere la paradoja de que el hábitat humano urbano es simultáneamente el único posible y tan ficticio, construido y alterable como una narración. En la historia de Silverberg, el proceso de urbanizar el mundo de una manera vertical resulta en un aumento considerable de espacio libre en la superficie del planeta, con lo que el número de habitantes se dispara hasta límites hoy inimaginables y la consigna bíblica del creced y multiplicaos se interpreta de manera literal. ${ }^{25}$ Las monurbs de Silverberg parecen tener muchos puntos de contacto con las arcologías propuestas por Paolo Soleri, de ahí que tengamos la creencia en que, para idear sus mónadas urbanas, Silverberg acudiera

\footnotetext{
${ }^{24}$ Funcionamiento silencioso (cat. ex.) ( 2003). Palacio de Cristal, Parque del Retiro, 30 enero-19 mayo de 2003, Museo Nacional Centro de Arte Reina Sofía, Madrid.

${ }^{25}$ El siguiente diálogo entre el habitante de una monurby un colono de Venus no tiene desperdicio alguno:

“_¿Cuál es la población de la planta 799? — pregunta Gortman.

-805, según las últimas informaciones.

—¿Y de Shanghái [conjunto de niveles, bautizados con antiguos nombres de ciudades]?

-Unos 50.000.

- ¿Y de la Monurb 116?

-881.000 .

— ¿Y hay cincuenta mónadas urbanas en esta constelación [agrupación de mónadas]?

- Sí ...

— ¿Y esta no es la mayor constelación, oh no, en absoluto! ...

-Es decir, una población global de...

—75.000.000.000 — pregona Mattern—. ¡Dios bendiga! ¡Nunca existió nada semejante! ¡Nadie sufre hambre! ¡Todo el mundo es feliz! ¡Hay cantidad de espacios libres! ¡Dios ha sido bueno con nosotros, Nicanor!”. Silverberg, Robert (1986). El mundo interior, Buenos Aires: Orbis, 13.
} 
a inspirarse en Arcology: The City in the Image of the Man, publicado en 1969, donde el arquitecto italiano presentaba un conjunto de proyectos de megaconstrucciones compatibles con el medio ambiente y los recursos naturales. ${ }^{26}$ En conformidad con sus propuestas Paolo Soleri intenta, desde la década de los setenta, realizar su teoría de una arquitectura distinta que provea de un urbanismo sostenible y ecológico; para ello se instaló en Scottsdale (Phoenix, Arizona), donde en pleno desierto ha levantado, mediante autofinanciaciones provenientes de cursos y talleres, el Arcosanti Project, un work-in-progress arquitectónico y atalaya conceptual desde los que difundir sus ideales utópicos. ${ }^{27}$

Teniendo en cuenta la creciente polución y las consecuencias ecológicas sufridas por el cambio climático, no parece absurdo ver que parte de ese táctica constructiva protectora comienza a perfilarse de modo nítido en la planificación urbana del presente, con tentativas muy definidas de mundos aislantes: parques temáticos que sirven para dilatar la sensación del acontecimiento ficticio del parque de atracciones; resorts, cuya función es ampliar la experiencia opiácea del lujo en el período vacacional; ciudades residenciales encapsuladas que, gracias a sus sistemas de seguridad, mantienen la ilusión de que la clase social alta apenas entra en contacto con el resto de la ciudad emponzoñada; o, finalmente, los centros comerciales y megastores que constituyen una síntesis diaria de todos los eventos imaginarios mencionados.

Las crisis de los años setenta proporcionó el caldo de cultivo idóneo para la emergencia de una oscuridad realmente tenebrosa en la década siguiente. Es probable, incluso, que se hicieran algunos esfuerzos para contrarrestar la rabia nihilista del punk con esa especie de "vuelta al orden clásico" que caracterizaría, por ejemplo, a la figuración de la transvanguardia italiana, al eclecticismo arquitectónico de fuerte raigambre grecolatina, a los neorrománticos y a los diseñadores modernos con coleta y hombreras. Sin embargo, la visión alterada de un futuro sucio y mugriento, representada en las páginas de la revista francesa Metal Hurlant a través de las ilustraciones apocalípticas de Jean Giraud

\footnotetext{
${ }^{26}$ Soleri, Paolo (1969). Arcology: The City in the Image of the Man, Cambridge, Mass. y Londres: The MIT Press.

${ }^{27}$ http://www.arcosanti.org/. Aún vigente en abril de 2010. Véase también el libro de Lima, Antonetta Iolanda (2003). Soleri: Architecture as Human Ecology, Nueva York: Monacelli Press.
} 
(Moebius), Philip Druillet, Enki Bilal, Juan Giménez o Jim Steranko, entre otros, constituyó el catalizador y el estímulo necesarios para la producción de un número sin fin de distopías. Así, mientras unos intentaban nadar hacia las tranquilas aguas del pensamiento débil de la "postmodernidad fría", ${ }^{28}$ otros, por el contrario, quedaban hipnotizados ante la contemplación del film de Ridley Scott Blade Runner (1982). ${ }^{29}$ La distopía como el paradigma arquitectónico y urbano sería ejemplificada en una ciudad de Los Ángeles, donde el estereotipo californiano sería pulverizado y reconvertido en un Hades contemporáneo. Ubicada en el futuro 2019, las soleadas playas de Venice Beach y las grandes extensiones suburbiales han sido sustituidas por una perenne lluvia ácida y la aglomeración urbana se encaja en arcologías y otras megaestructuras. Tras ella, las ciudades lluviosas y oscuras proliferaron como los hongos en los años siguientes: Robocop (Paul Verhoeven, 1987), Johnny Mnemonic (Robert Longo, 1995), The Matrix (Larry y Andy Wachowsky, 1997) o Dark City (Alex Proyas, 1998);30 hasta George Lucas hace su particular homenaje a la visión scottiana de Los Ángeles en las panorámicas nocturnas del planeta ciudad Coruscant en las últimas entregas de la saga Star Wars.

Construida Blade Runner con un inconfundible sabor a cine negro, desfilan por ella los personajes-con caracteres psicológicos cada vez más cercanos a nosotros-del siglo XXI. Un hastiado detective explica en la característica voz en off las peculiaridades de la compleja Cityspeak (en España rebautizada como "Interlingua"): "la jerga que habla es interlingua, un argot, una mezcolanza de francés, inglés, italiano, español y lo que sea. En realidad, yo no necesitaba

\footnotetext{
${ }^{28}$ Guasch, Anna (2000). El arte último del siglo XX. Del minimalismo a lo multicultural, Madrid: Alianza.

${ }^{29}$ Blade Runner, en tanto que película de culto, ha generado numerosos textos entre los que queremos resaltar los siguientes: el imprescindible libro de Paul M. Sammon (1996). Future Noir. The Making of Blade Runner, Nueva York: Harper; existe traducción al castellano (2005). Cómo se hizo Blade Runner: Futuro en negro, Madrid: Alberto Santos Editor. En el ámbito español merece la pena destacar una obra colectiva en la que la intelectualidad de la época aportaba su visión hacia el universo de Ridley Scott, AA VV (1996). Blade Runner, Barcelona: Tusquets; finalmente, el desigual texto de Jaime Gorostiza y Ana Pérez (2002). Blade Runner. Ridley Scott, Barcelona: Paidós.

${ }^{30} \mathrm{~A}$ este respecto véase el documental adjunto a los extras del DVD editado con motivo de la versión final de Blade Runner. The Final Cut, titulado Dangerous Days: Making Blade Runner (2007), donde variados cineastas y directores de videoclip expresan la deuda que tienen con el imaginario urbano heredado del film de Ridley Scott.
} 
traductor: conocía esa jerga". Si se cambia el referente lingüístico por el arquitectónico podremos hacernos una idea bastante aproximada del absoluto eclecticismo que impera en sus imágenes. Decisiones atinadas en el diseño de producción de la película se constituyen por revisiones visuales como son la cita del edificio cuasicilíndrico de Metrópolis-sede del ficticio clan Fredersen-en el rascacielos de la estación de policía (cuyo interior son las instalaciones de la real estación ferroviaria Union Station, en Los Ángeles), el uso de una construcción tan conocida como el Bradbury Building (1893) desde una perspectiva inédita, o la inclusión de elementos ajenos a la fachada de los edificios, que van de variadas conducciones a pantallas gigantes de proyección de anuncios publicitarios. Pero, sin duda, el gran acierto en la producción artística fue la transferencia a la pantalla del diseño de las pirámides Tyrell, sede del monopolio del comercio de replicantes en ese tiempo futurible. Fruto de la imaginación del ya citado Douglas Trumbull, estas dos pirámides de planta cuadrada (dispuestas en diagonal una con respecto de la otra, como las de Keops, Kefrén y Micerinos) están conformadas por dos escalones que evocan más las formas de la mesoamericana pirámide de Teotihuacan que la de Saqqara. Dos torres, elevadas paralelamente con el mismo grado de inclinación que la pirámide, jalonan cada lado de la misma; y la organización de la piel del edificio revela un grado de preciosismo que recuerda a las perforaciones murarias del gótico flamígero. No obstante, son sumamente interesantes las concomitancias formales de dichas torres y el parentesco visual entre el diseñador Douglas Trumbull (1980) y un nonagenario Philip Johnson que se aferra con fuerza a las Torres Puerta de Europa (Madrid, 1996). ¿Se podría afirmar taxativamente que no ha habido algún tipo de contaminación visual/conceptual en la génesis del proyecto de Johnson?

Los años noventa del siglo pasado conocieron una multiplicación de los discursos arquitectónicos íntimamente conectados con la exploración de las posibilidades fantásticas del medio. En efecto, si atendemos a los modos en los que se manifiesta la expresión gráfica arquitectónica, es decir, al proyecto imaginado que el arquitecto utiliza como una idealización pictórica del espacio construido, podremos comprobar que muchas de ellas están contaminadas de la percepción tecnofantástica. Un ejemplo recurrente podría ser un formidable plano general tomado de Blade Runner. La sombra de las torres que jalonan la pirámide Tyrell queda recortada a contraluz delante de un cielo rojizo, producto del sol poniente; 
en contraposición, se puede citar como respuesta "real" el proyecto de 1997 de los arquitectos españoles María Rosa Cervera y Javier G. Pioz para Shanghái: la silueta de la Torre Biónica se define en un contraluz de las mismas características. ${ }^{31}$

Más patrones se suman al modelo de apropiación de la imagen fantástica en ejecuciones reales durante estos años. Prueba de ello serían los ecos metabolistas de Kenzo Tange (muy influido por la arquitectura pop de Archigram) en el edificio de la Fuji TV (Tokio, 1997); o la "varita mágica" arquitectónica que supuso la institución y construcción del Museo Guggenheim Bilbao en 1997, propuesta por la visión absolutamente delirante y barroca de un Frank Gehry en estado de gracia. El arte contemporáneo no es ajeno a esta apropiación del patrimonio fantástico y se suma con propuestas ciertamente apasionadas y no carentes de humor, como es el caso de los proyectos de urbanismo afroutópico del artista congoleño Bodys Isek Kingelesz entre los que destacan Kimbeville Ihunga o New Manhattan 3001, de los años 1993-94. En ellas, Kingelesz despliega una propuesta de megalópolis que se encuentra a medio camino entre lo kitsch, el pop y la crítica a un entorno tan depauperado y tan desigual como es el continente africano. $^{32}$

El desigual optimismo hacia la arquitectura provoca la generación de imágenes, sobre todo desde el medio cinematográfico, en las que se propone el crecimiento previsible de ciertas ciudades, como es el caso del París del año 2054 donde el diseñador Christian Volkman revisa las tesis de la citada ville spatiale de Friedman en Renaissance (Mathieu Delaporte, 2006), un thriller de animación que aporta una visión interesante del desarrollo urbanístico futurista, como la cubrición completa del Sena por un grueso cristal protector. De manera similar, y para introducir la última parte de nuestro discurso, se podría citar el diseño de John Frazer para la película Bicentennial Man (El hombre bicentenario) dirigida por Chris Columbus en 1999. Uno de los planos muestra el sempiterno Puente de Brooklyn desde donde se aprecia en su esplendor el skyline neoyorkino con

\footnotetext{
${ }^{31}$ Véanse los siguientes websites: http://www.torrebionica.com/y http://www.cerveraandpioz.com/. Aún vigentes en abril de 2010.

${ }^{32}$ Moriente, David (2010). Poéticas arquitectónicas en el arte contemporáneo, 1970-2008, Madrid: Cátedra.
} 
nuevos rascacielos de apuntadas agujas-muy futuristas en el sentido sant'eliano-y, he aquí lo interesante, una reactualización del World Trade Center traducida en el aumento de altura de las torres en más del doble.

Merece la pena detenerse un momento en la paradoja que trae consigo el contemplar estas imágenes. Dado que la fecha del 11 de septiembre de 2001 supuso un cambio espectacular (en los dos sentidos) en la noción del mundo contemporáneo, estos fantasmas arquitectónicos han funcionado como un punto sobre el que pivota, por un lado, la misma noción de postmodernidad: si en 1972 Charles Jencks dictó el acta de defunción de la arquitectura moderna, a través de la demolición de los Pruitt-Igoe de Sant Louis, la disolución de otro edificio de Yamasaki en la cumbre del poder financiero en Nueva York centra su foco en la pulsión edificatoria, más empeñada en registrar récords de altura y en construir edificios simbólicos antes que funcionales. ${ }^{33}$ La demostrucción (en palabras de Juan Antonio Ramírez ${ }^{34}$ ) del WTC, por consiguiente, debería hacer reflexionar si aquella postmodernidad arquitectónica fue, en realidad, una solución a los problemas de base del urbanismo contemporáneo.

La demolición (controlada o no) del WTC sirvió de base para que al menos algunos, como en el caso del estudio arquitectónico de Vito Acconci, Acconci Studio, se plantearan la alternativa a una arquitectura demasiado deshumanizada para ser percibida como un elemento común para todos los ciudadanos. Así, en 2002, exhibieron el proyecto de un nuevo World Trade Center que sirviera como centro de la comunidad de neoyorkinos, con parques elevados y lugares de reunión. Este nuevo WTC contaba con una particularidad ciertamente satírica: la

\footnotetext{
${ }^{33}$ En el momento de revisar este texto, llama mi atención un artículo profusamente ilustrado sobre el futuro centro cultural, sin nombre aún, construido por el centenario arquitecto brasileño Oscar Niemeyer. Todo son vaguedades sobre la finalidad del edificio, pues servirá para cualquier eventualidad que se presente, pero sobre todo “ahora, después del drama de la reconversión económica de los noventa, Avilés empuja envalentonado por la sombra del centro Niemeyer hacia la segunda transformación económica de su historia: la conquista definitiva de los servicios. Porque a nadie se le escapa en el municipio que el nuevo edificio será un foco de atracción de turistas. Los restaurantes del casco histórico han traducido sus cartas al inglés, y de los tres hoteles que había en 2000 se ha pasado ya a los diez. Y los que vendrán”. VERDÚ, Daniel, “Todas las artes caben en el Niemeyer”, El País Semanal, 1.752, 25 de abril de 2010, pp. 22-27.

${ }^{34}$ Léase Ramírez, Juan Antonio (2006). “De la ruina a la destrucción arquitectónica (Para una iconografía del caos)". En La multiculturalidad en las artes y en la arquitectura, Las Palmas de Gran Canaria: Actas del XVI Congreso del CEHA, , 525-553.
} 
estructura del edificio estaba subordinada a sus gigantescos agujeros. Como afirma el mismo Acconci "si, en los tiempos que corren, es inevitable que a un edificio lo hagan saltar por los aires, un edificio nuevo ya podría venir preexplotado... Frente a un edificio privado, aquí plazas y jardines se introducen en el edificio. Lo público y lo privado se entremezclan". ${ }^{35}$

De este modo, en nuestro actual siglo XXI se solapan distintos modos de comprender la arquitectura, como modelo regenerador-heredero de la modernidad-y como símbolo del poder. Los trabajos de Santiago Calatrava se insertan, creemos, en el paradigma de este último aspecto. No hay más que echar un vistazo al área de influencia de la Ciutat de les Arts i les Ciències de Valencia (1998-2005) que ha visto considerablemente aumentado el valor de su suelo o a la Turning Torso, en Malmö (Suecia), donde la obstinación constructiva del arquitecto sobrepasa con creces otros valores necesarios, como la funcionalidad. ${ }^{36}$ El hedonismo arquitectónico de Calatrava, con su organicismo repetitivo y modular, ha permeado la nueva imagen fantástica, prueba de ello lo demuestran los escenarios urbanos calatravantes de la ciudad-estado de ECOBan en Wonderful Days, largometraje de animación de los coreanos Moon-saeng Kim y Park Sunmin (2003) o, más recientemente, en el remake de la serie televisiva $V$ (1983), dirigida por Kenneth Johnson en 2009, donde el interior de las naves nodriza extraterrestres (diseño de producción de Susan Parker y Stephen Geaghan) se expone rezumante de ese aspecto orgánico tan proclive a Calatrava.

Después de todas estas expresiones alucinatorias, no queríamos terminar sin hacer notar que, a pesar de los referentes arquitectónicos de alta tecnología, hay reflexiones que toman como punto de partida la imagen de la autoconstrucción precaria o, dicho de otro modo, la chabola. Parecería que a la ciencia ficción no le interesa el correlato con el desecho, pero no es así; podríamos citar algunos ejemplos tomados del subgénero del cine postapocalíptico, donde Mad Max

\footnotetext{
${ }^{35}$ Cfr. "Calles, edificios, plazas", en Acconci Studio, Interiors, Buildings, Parks (DVD), MACBA, Museo de Bellas Artes de Nantes, Barcelona, Nantes, 2004, min. 20-22. Transcripción nuestra. ${ }^{36}$ El cineasta Fredrik Gertten hace un retrato un tanto ominoso de Santiago Calatrava en el documental The Socialist, the Architect, and the Twisted Tower (2005). Asimismo léase la polémica por el grave daño moral que sufrió porque habían alterado su obra, el puente de ZubiZuri, para que fuera más funcional. "Bilbao, condenado a indemnizar a Calatrava por 'alterar su obra”, en El País, 11 de marzo de 2009, sección Cultura.
} 
Beyond Thunderdome (Mad Max III. Más allá de la cúpula del trueno, George Miller y George Ogilvie, 1985) sería el paradigma de la re-creación gracias a los vestigios dejados por la antigua sociedad: en una suerte de medievo tecnológico, la delicada utopía del reciclaje y el trueque se llama, paradójicamente, Negociudad. Más interesante aún nos parece la separación de los habitantes en el anime Battle Angel Alita (Yukiro Kishito, 1990). El escenario de la narración está dividido en dos ciudades: una, flotante, Tiphares (o Zalem, según las versiones)—con una estructura similar a los proyectos de colonia toroidal espacial del ingeniero de la NASA Gerard K. Neill o, más aún, al diseño de la ciudad de Bespin para El Imperio contraataca (Irving Keshner, 1981)-donde vive la élite dominante y otra en el suelo, Zukutetsu, organizada alrededor de la gigantesca montaña de desperdicio que genera y abandona la ciudad celeste y que es donde viven los excluidos. La dicotomía entre el derroche y el aprovechamiento conduce a que la arquitectura se desdoble de manera radical.

El uso del referente en tanto que contraposición con la ciudad noble, es decir, la institución de espacios para-urbanos al margen urbano, más allá de sus límites se ha extendido considerablemente. Podríamos traer a colación Miracolo a Milano (Milagro en Milán, Vittorio de Sica, 1951) como precedente visual del uso de ese urbanismo efímero, amenazado constantemente; pero también la atracción/repulsión que supone contemplar la magnitud colosal de la Favela Rocinha en Río de Janeiro o las fachadas ilegales en Hong Kong se traducen a la producción visual, donde Dionisio González o Marjetica Potrč serían algunos ejemplos de artistas seducidos por esa belleza sucia, desgastada y efímera. 